\title{
Efficacy of a virtual reality-based basic and clinical fused curriculum for clinical education on the lumbar intervertebral disc
}

\author{
*Fangfang Qi, PhD, ${ }^{1-3}$ Yixiang Gan, BS, ${ }^{4}$ Shengwen Wang, PhD, ${ }^{5,6}$ Yizhe Tie, BS, ${ }^{7}$ \\ Jiewen Chen, BS, ${ }^{8}$ and Chunhai $\mathrm{Li}, \mathrm{MD}^{1,8}$ \\ ${ }^{1}$ Teaching and Research Bureau of Surgery, Sun Yat-sen Memorial Hospital, Sun Yat-sen University; ${ }^{2}$ Department of Anatomy \\ and Neurobiology, Zhongshan School of Medicine, Sun Yat-sen University, Guangzhou; ${ }^{3}$ Guangdong Province Key Laboratory of \\ Brain Function and Disease, Zhongshan School of Medicine, Sun Yat-sen University, Guangzhou; ${ }^{2}$ School of Medicine, Sun Yat- \\ sen University, Shenzhen; ${ }^{5}$ Department of Neurosurgery, Sun Yat-sen Memorial Hospital, Sun Yat-sen University, Guangzhou; \\ ${ }^{6}$ Guangdong Provincial Key Laboratory of Malignant Tumor Epigenetics and Gene Regulation, Sun Yat-sen Memorial Hospital, \\ Sun Yat-sen University, Guangzhou; ' Zhongshan School of Medicine, Sun Yat-sen University, Guangzhou; and ${ }^{8}$ Department of \\ Orthopedics, Sun Yat-sen Memorial Hospital, Sun Yat-sen University, Guangzhou, Guangdong, China
}

\begin{abstract}
OBJECTIVE Today, minimally invasive procedures have become mainstream surgical procedures. Percutaneous endoscopic transforaminal discectomy for lumbar disc herniation (LDH) requires profound knowledge of the laparoscopic lumbar anatomy. Immersive virtual reality (VR) provides three-dimensional patient-specific models to help in the process of preclinical surgical preparation. In this study, the authors investigated the efficacy of VR application in LDH for training orthopedic residents and postgraduates.
\end{abstract}

METHODS VR images of the lumbar anatomy were created with immersive VR and mAnatomy software. The study was conducted among 60 residents and postgraduates. A questionnaire was developed to assess the effect of and satisfaction with this VR-based basic and clinical fused curriculum. The teaching effect was also evaluated through a postlecture test, and the results of the prelecture surgical examination were taken as baselines.

RESULTS All participants in the VR group agreed that VR-based education is practical, attractive, and easy to operate, compared to traditional teaching, and promotes better understanding of the anatomical structures involved in LDH. Learners in the VR group achieved higher scores on an anatomical and clinical fusion test than learners in the traditional group ( $84.67 \pm 14.56$ vs $76.00 \pm 16.10, p<0.05)$.

CONCLUSIONS An immersive VR-based basic and clinical fused curriculum can increase residents' and postgraduates' interest and support them in mastering the structural changes and complicated symptoms of LDH. However, a simplified operational process and more realistic haptics of the VR system are necessary for further surgical preparation and application.

https://thejns.org/doi/abs/10.3171/2021.5.FOCUS20756

KEYWORDS virtual reality; lumbar disc herniation; cauda equina syndrome; clinical education

$\mathrm{T}$ ODAY, minimally invasive procedures have become mainstream surgical procedures. Since 2015, the Sun Yat-sen University (Guangzhou, China) has introduced the theory of planning basic and clinical deep integration and promoted the construction of a world-class medical university. Vertical integration between basic sciences and clinical medicine in a case-based learning context may better promote profound rather than short-term or superficial study, and thereby promoting better under- standing of important medical principles and/or surgical procedures. Subsequently, simulated endoscopy training, animal endoscopy training, and clinical endoscopic practice in human beings were gradually developed by the Zhongshan School of Medicine and several hospitals affiliated with the Sun Yat-sen University. Furthermore, clinicians need to receive three-dimensional (3D) spatial thinking training before performing endoscopic surgery. ${ }^{1,2}$ Lumbar disc herniation (LDH) treatment is an important

ABBREVIATIONS $2 \mathrm{D}=$ two-dimensional; $3 \mathrm{D}=$ three-dimensional; $\mathrm{LDH}=$ lumbar disc herniation; $\mathrm{PETD}=$ percutaneous endoscopic transforaminal discectomy; $\mathrm{VR}=$ virtual reality.

SUBMITTED August 24, 2020. ACCEPTED May 18, 2021

INCLUDE WHEN CITING DOI: 10.3171/2021.5.FOCUS20756.

${ }^{*}$ F.Q., Y.G., and S.W. contributed equally to this work. 
training branch of surgery and requires complicated and difficult surgical procedures. ${ }^{3}$ Percutaneous endoscopic lumbar discectomy/percutaneous endoscopic transforaminal discectomy (PETD) has proved to be a safe and therapeutically effective intervention for LDH. It also has clinical outcomes similar to those following conventional open microdiscectomy. ${ }^{4,5}$ The progress of surgical technology enables the application of PETD for LDH surgery, which increases the training requirements for surgeons.

However, clinical anatomy education in the medical colleges and universities of China has shown a trend of fewer teaching hours, less trained faculty, and limited cadaver dissection. ${ }^{6,7}$ Moreover, two-dimensional (2D) anatomical atlases and lecture notes are still the typical pedagogical tools for teaching clinical anatomy to medical students. LDH surgery is highly difficult because of the complicated and fragile neuroanatomy involved. The cultivation of a mature surgeon requires a long period of training. However, a medical student's understanding of the procedure is often limited to a verbal description or a $2 \mathrm{D}$ representation. Therefore, when junior surgeons attempt endoscopic surgery (e.g., PETD for LDH), their anatomical knowledge is based on 2D lessons that do not enable them to fully understand the complicated structure involved in this surgery.

In recent years, virtual reality (VR), as an evolution of digital technology, has enabled creative solutions for clinical education, diagnosis, and treatment ${ }^{6,8,9}$ and thus has become a potentially beneficial tool for clinical medicine. ${ }^{10,11}$ VR can provide a vast number of hands-on opportunities for medical students to practice operations, ${ }_{12,13}$ clinical skills training, and physical rehabilitation. ${ }^{14,15}$ Gerardi et al. have suggested that VR creates "a sense of presence in an immersive, computer-generated, three-dimensional, interactive environment." 16 This is achieved through head-mounted displays, body-tracking sensors, and direct user-input devices. Moreover, Jacobsen et al. have also reported that the VR simulator performance of surgeons is positively associated with their real-life cataract surgical performance. ${ }^{17}$

In the field of neurosurgery, VR technology has been increasingly applied in clinical practice. ${ }^{18,19}$ Studies have begun to investigate the feasibility and effects of VR application in neurosurgical education. ${ }^{20-22} \mathrm{~A}$ recent study has shown that VR technology might improve the quality of teaching on the neurosurgical skull base for clinical undergraduates, suggesting that it should be promoted when teaching clinical subjects. ${ }^{23}$ Therefore, in the present study, we investigated whether the use of VR-based training applications could help residents and postgraduates obtain a better understanding of anatomical knowledge, 3D positions in space, and adjacent relationships in the standard anatomical structure of the lumbar region and $\mathrm{LDH}$.

\section{Methods \\ Participants}

A total of 60 students of clinical medicine were recruited for this research. All participants were selected from postgraduates and residents at the Sun Yat-sen Memorial Hospital, who had previously received the same training.
TABLE 1. Demographic characteristics of the VR teaching group and traditional group

\begin{tabular}{lcc}
\hline \multicolumn{1}{c}{ Variable } & VR Teaching Group & Traditional Group \\
\hline Male & $14(46.67 \%)$ & $13(43.33 \%)$ \\
\hline Female & $16(53.33 \%)$ & $17(56.67 \%)$ \\
\hline Age $($ yrs $)$ & $23.50 \pm 1.41$ & $23.87 \pm 1.67$ \\
\hline Surgery score & $72.54 \pm 7.27$ & $71.27 \pm 8.75$ \\
\hline p value & $>0.05$ for all above & $>0.05$ for all above \\
\hline
\end{tabular}

Values are presented as the number $(\%)$ of patients or the mean $\pm S D$, unless indicated otherwise. A p value $<0.05$ represents a statistical difference between the two groups.

None of them had previously been exposed to VR teaching. Since 2014, both clinical postgraduates and residents have received standardized training and taken courses in China. Therefore, they could be considered as homogeneous participants in this study. The participants were randomly divided into two groups. Thirty of the participants attended VR lesson training (VR teaching group). These trainees, 14 males and 16 females, were 22-26 years old. The other 30 participants, including 13 males and 17 females, were assigned to the traditional teaching group as controls. Both groups had the same syllabus and study tasks. All recruited trainees completed this research, and no data were withdrawn. No gender or age difference was found between the VR teaching group and the traditional group ( $\mathrm{p}>0.05$; Table 1$)$.

\section{VR Model Design}

The 3D images for standard lumbar anatomy were transformed from images from the textbook Regional Anatomy, 8th Edition, published by the People's Medical Publishing House (Fig. 1). DICOM 3.0 data sets from a 64-slice spiral CT (Sensation 64, Siemens Medical Systems) were collected from a patient (male, 53 years old) in the orthopedics department at Sun Yat-sen Memorial Hospital, Guangzhou, China. These data sets were applied to generate the digital model for $\mathrm{LDH}$.

The following scanning settings were used: $120 \mathrm{kV}$, $200 \mathrm{mAs}, 1.0-\mathrm{mm}$ slice. The following algorithms were used: filtered backprojection; SAFIRE kernel: B20f smooth; window: spine; w: 300, L: 60; B70f smooth; window: bone; w: 2400, L: 900; and FOV: $220 \times 226 \mathrm{~mm}$. DICOM 3.0 data were imported to mVR 3.1 software (M Visioner Technology Co.) to create a standard 3D lumbar vertebra model. Then the VR images of the lumbar region, including bone, intervertebral disc, nerve root, muscle, ligament, and adjacent arteriovenous structures, were carefully drawn by mAnatomy software 3.3.1 (M Visioner Technology Co.). Next, Maya 2020 (Autodesk Inc.) was used to refine the 3D models, and then the individual files were exported in the FBX format. Special eyeglass lenses were used to visualize VR. Each part of the drawn model was independent of every other part of the model, and anatomical relationships of different structures could be prominently displayed by separating and combining the parts. Surgical instruments were also connected to this 


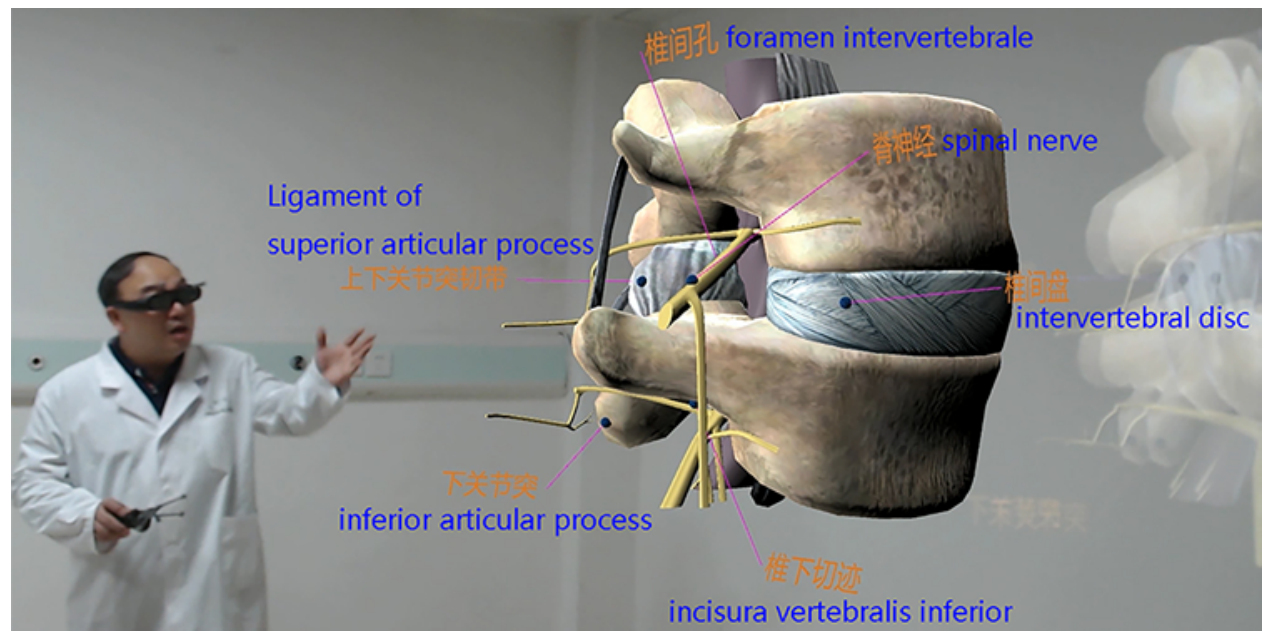

FIG. 1. The model for standard lumbar anatomy used in this study. Residents and medical students are fully immersed in a virtual environment that mimics the characteristics of real human anatomy through 3D glasses.

system to simulate real surgery practices by adjusting the direction and position of instruments.

\section{Teaching Methods and Evaluation}

The traditional teaching group participated in $2 \mathrm{D}$ lecture-based teaching, which included anatomical structure, clinical case-based learning, and videos of the surgical procedure in LDH. In the VR teaching group, however, trainees immersed themselves in the virtual space and observed simulation models of both standard 3D lumbar vertebra and LDH. Each lesson lasted 40 minutes. A questionnaire was developed to assess satisfaction with VR simulation for clinical medicine teaching (Table 2). The questionnaire contained 10 questions. The construct validity assessed by factor analysis and three factors (selfgains, applicability, study activities) were obtained, which accounted for $41.73 \%, 17.04 \%$, and $22.24 \%$ of the total variance, respectively. Cronbach's $\alpha$ was 0.860 . All questions were single choice, using a 5-point Likert scale that ranged from "strongly agree" (5 points) to "strongly disagree" (1 point).

When comparing the teaching results, we used the scores from a previous examination of orthopedic surgery as baselines in view of their availability and the contiguity in time to this VR teaching. The baseline test contained four parts: part I, single answer (30 points); part II, term explanation ( 25 points); part III, short-answer questions (24 points); and part IV, essay discussion (21 points). After the lessons, all of the trainees were required to complete a simpler, single-choice test of anatomical and clinical fusion to evaluate their acquired knowledge during the lessons. The results were collected and analyzed to assess their current understanding of diagnosis, treatment, and anatomy of the spine. All participants were asked to read a research statement and they provided informed consent.

\section{Ethical Considerations}

This research was approved by the Research Ethics
Committee of the Sun Yat-sen University Memorial Hospital, Sun Yat-sen University, and was conducted according to the Helsinki declaration.

\section{Data Analysis}

Statistical analyses of the test scores and rate were conducted using the IBM SPSS Statistics package version 23.0 (IBM Corp.). An independent-samples t-test (2-tailed) was used to evaluate the differences in test scores between the two groups. Fisher's chi-square analysis (2-tailed) was used to evaluate the differences in failure rate and high score rate because the sample size was less than 40. Data for the statistical analyses were presented as the mean \pm standard deviation, and $\mathrm{p}<0.05$ was considered to indicate a statistically significant difference from controls.

\section{Results}

\section{Digital Model for Standard Lumbar Anatomy and LDH}

The 3D images were transformed from standard textbook images (Fig. 1). In this way, residents and students could view a $3 \mathrm{D}$ vertebral column true to nature. The system enabled users to freely reach for the 3D image as if it floated in front of them. The images were controlled by electromagnetic sensors placed in handles and a stylus located in the left and right hands, respectively.

The virtual anatomy model included bones, intervertebral discs, nerve roots, muscles, ligaments, and adjacent arteriovenous structures. It is color-coded to distinguish the regional neuroanatomy, and all virtual parts could be freely rotated, zoomed, shifted, and navigated by toggling dozens of built-in annotations. The model allowed users to conveniently observe the regional structures and gain a better understanding of their potential relationships and clinical significance.

\section{Digital Anatomical Model for LDH}

A hospitalized patient (male, 53 years old) was ran- 
TABLE 2. Evaluation scale for VR technology in LDH

\begin{tabular}{|c|c|c|c|c|c|c|c|c|c|c|c|}
\hline \multirow[b]{2}{*}{ Question } & \multicolumn{5}{|c|}{ No. (\%) } & \multirow{2}{*}{$\begin{array}{l}\text { Total No. of } \\
\text { Respondents }\end{array}$} & \multirow{2}{*}{$\begin{array}{c}95 \% \\
\mathrm{Cl}\end{array}$} & \multirow{2}{*}{$\begin{array}{c}p \\
\text { Value }\end{array}$} & \multirow{2}{*}{$\begin{array}{c}\text { Factor } \\
1\end{array}$} & \multirow{2}{*}{$\begin{array}{l}\text { Factor } \\
2\end{array}$} & \multirow{2}{*}{$\begin{array}{c}\text { Factor } \\
3\end{array}$} \\
\hline & 5 Points & 4 Points & 3 Points & 2 Points & 1 Point & & & & & & \\
\hline $\begin{array}{l}\text { V1. VR technology is } \\
\text { practical in LDH educa- } \\
\text { tion }\end{array}$ & $83.33(25)$ & $16.67(5)$ & $0(0)$ & $0(0)$ & $0(0)$ & 30 & $1.69-1.97$ & $<0.001$ & & & 0.807 \\
\hline $\begin{array}{l}\text { V2. VR technology pro- } \\
\text { motes understanding of } \\
\text { topography of the lumbar } \\
\text { anatomy }\end{array}$ & $83.33(25)$ & $16.67(5)$ & $0(0)$ & $0(0)$ & $0(0)$ & 30 & $1.69-1.97$ & $<0.001$ & & 0.707 & \\
\hline $\begin{array}{l}\text { V3. VR technology can } \\
\text { give me further under- } \\
\text { standing of the innerva- } \\
\text { tion of lumbar nerves }\end{array}$ & $83.33(25)$ & $16.67(5)$ & $0(0)$ & $0(0)$ & $0(0)$ & 30 & $1.69-1.97$ & $<0.001$ & & 0.550 & \\
\hline $\begin{array}{l}\text { V4. VR technology has } \\
\text { advantages over tradi- } \\
\text { tional anatomy books in } \\
\text { studying }\end{array}$ & $90.00(27)$ & $10.00(3)$ & $0(0)$ & $0(0)$ & $0(0)$ & 30 & $1.79-2.01$ & $<0.001$ & & 0.616 & \\
\hline $\begin{array}{l}\text { V5. Interacting with the } \\
\text { system is sometimes } \\
\text { frustrating }\end{array}$ & $20.00(6)$ & $20.00(6)$ & $23.33(7)$ & $23.33(7)$ & $13.33(4)$ & 30 & -0.40 to 0.60 & 0.687 & & & 0.613 \\
\hline $\begin{array}{l}\text { V6. The teaching pattern } \\
\text { based on VR is attractive }\end{array}$ & $63.33(19)$ & $36.67(11)$ & $0(0)$ & $0(0)$ & $0(0)$ & 30 & $1.45-1.82$ & $<0.001$ & 0.724 & & \\
\hline $\begin{array}{l}\text { V7. VR system is easy to } \\
\text { operate on }\end{array}$ & $56.67(17)$ & $43.33(13)$ & $0(0)$ & $0(0)$ & $0(0)$ & 30 & $1.38-1.75$ & $<0.001$ & & & 0.747 \\
\hline $\begin{array}{l}\text { V8. VR system increases } \\
\text { the interaction between } \\
\text { teacher and me }\end{array}$ & $73.33(22)$ & $23.33(7)$ & 3.33 (1) & $0(0)$ & $0(0)$ & 30 & $1.50-1.90$ & $<0.001$ & 0.807 & & \\
\hline $\begin{array}{l}\text { V9. VR system promotes } \\
\text { interest in learning } \\
\text { anatomy lesson }\end{array}$ & $70.00(21)$ & $26.67(8)$ & $3.33(1)$ & $0(0)$ & $0(0)$ & 30 & $1.46-1.87$ & $<0.001$ & 0.792 & & \\
\hline $\begin{array}{l}\text { V10. VR system helps to } \\
\text { understand the course } \\
\text { of clinical diagnosis and } \\
\text { treatment }\end{array}$ & $73.33(22)$ & $23.33(7)$ & 3.33 (1) & $0(0)$ & $0(0)$ & 30 & $1.50-1.90$ & & 0.807 & & \\
\hline $\begin{array}{l}\text { Variance contribution } \\
\text { rate }\end{array}$ & & & & & & & & & $41.73 \%$ & $17.04 \%$ & $22.24 \%$ \\
\hline
\end{tabular}

Five-point Likert scale: 1 point = strongly disagree; 2 points = disagree; 3 points = neutral; 4 points = agree; 5 points = strongly agree. Factor 1: self-gains; factor 2: study activities; factor 3 : applicability. A p value $<0.05$ represents a statistical difference between the two groups.

domly chosen from the orthopedics department of the Sun Yat-sen Memorial Hospital, Sun Yat-sen University (Fig. 2). This patient was chosen based on the presentation of typical symptoms associated with $\mathrm{LDH}$, and he signed informed consent to participate in this research. The patient had long been suffering from low-back pain and leg pain, with symptoms of paresthesia and numbness of the anterior leg, dorsal foot, and digitus medius pedis, as well as weakness of the gluteus medius, extensor longus pollicis, and flexor digitorum longus muscles. The patient also complained of perineal numbness, defecation difficulty, and sexual hypoactivity, which are classic manifestations of the cauda equina syndrome. Physical examination yielded a positive Lasègue's test and showed absent tendon reflex. All of these symptoms led to the diagnosis of LDH between L4 and L5, which was then confirmed with CT and MRI. The 3D model of this case was created with mVR software, in which the primary data of DICOM 3.0 of the CT were imported into the software system and then loaded into the VR environment to perform a virtual 3D reconstruction of the vertebral column. The 3D model also included the positions of protrusions and the distribution of the gluteus medius, extensor longus pollicis, and flexor digitorum longus muscles innervated by the L5 nerve in central-type LDH (Fig. 3).

\section{Assessment of the VR System for Clinical Teaching of Regional Anatomy}

After the lecture, a questionnaire (Table 2) was immediately completed by trainees in the VR teaching group to measure their satisfaction with VR learning. All 30 participants finished the survey, which revealed that the 


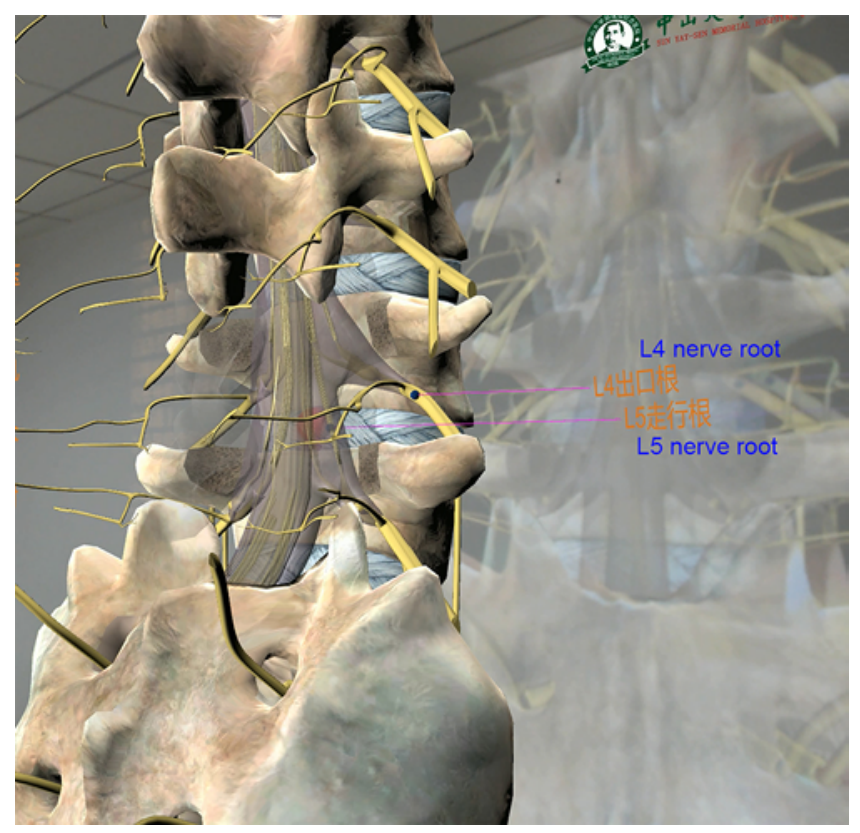

FIG. 2. The clinical case of central-type LHD used in this study. The protrusion (red area) was shown in the middle of the intervertebral disc between L4 and L5. Protrusion pinch on L5 nerve root.

students benefited from the immersive VR teaching format. A large percentage of the group (83.33\%) strongly agreed and $16.67 \%$ agreed with the viewpoint that VR technology is practical. Moreover, $83.33 \%$ strongly agreed and $16.67 \%$ agreed with the viewpoint that VR technology promotes understanding of the topography of the lumbar anatomy. Similarly, 83.33\% strongly agreed and $16.67 \%$ agreed with the viewpoint that VR technology can increase their understanding of the distribution and path of the lumbar nerves. An even higher percentage $(90.00 \%)$ of the students strongly agreed and $10.00 \%$ agreed with the viewpoint that VR technology offers advantages over traditional anatomy books in studying. However, $63.33 \%$ strongly agreed and $36.67 \%$ agreed with the viewpoint that the teaching pattern based on VR is attractive, $56.67 \%$ strongly agreed and $43.33 \%$ agreed with the viewpoint that the system is easy to operate, and $73.33 \%$ strongly agreed and $23.33 \%$ agreed with the viewpoint that the VR system increases the interaction between teacher and learners (only 1 participant remained neutral). Interestingly, $96.67 \%$ of students claimed that VR promoted their interest in learning anatomy lessons. Finally, $73.33 \%$ strongly agreed and $23.33 \%$ of students agreed with the opinion that this VR system may help them understand the course of clinical diagnosis and treatment in the future. However, when asked whether interacting with the system is sometimes frustrating, the learners' answers showed an obvious difference of opinion: $20.0 \%$ strongly agreed, $20.00 \%$ agreed, $23.3 \%$ remained neutral, $23.33 \%$ disagreed, and $13.33 \%$ strongly disagreed with this viewpoint. These findings show that there were no obvious differences in the number of students holding each of these five opinions, suggesting good discrimination of this item ( $p>0.05$; Table
2). No other obvious issues were reported by participants in the VR teaching group.

\section{Anatomical and Clinical Fusion Knowledge Test Scores}

Prior to the VR teaching lesson, the orthopedic surgery scores of participants were obtained, and no significant differences were found between participants in the VR teaching group and those in the traditional teaching group (Fig. $4 \mathrm{~A} ; 72.54 \pm 7.27$ vs $71.27 \pm 8.75$, respectively, $\mathrm{p}>$ $0.05)$. However, after the lesson, the test scores of students in the VR teaching group were significantly higher than those of students in the traditional group (Fig. 4B; $84.67 \pm$ 14.56 vs $76.00 \pm 16.10, p<0.05)$. No significant difference was found in the failure rate $(<60)$ between the two groups ( $0.00 \%$ for the VR group, $3.33 \%$ for the control group). The high score rate $(>80)$ was higher in the VR teaching group (83.33\%) than in the control group (63.33\%), but this effect did not reach statistical significance (Fig. 4C and D; $\mathrm{p}=0.143$ ).

\section{Discussion}

The basic and clinical fused curriculum contains both anatomical knowledge and clinical diagnosis and treatment therapies. Although it has been previously reported that tablet-based 3D models and VR devices could provide useful supplementary tools for medical undergraduates, ${ }^{23-25}$ the learning effects for resident doctors and postgraduates when using such a VR fused curriculum remain unclear. The present study shows that the majority of participants accepted VR as an effective teaching method in their clinical education of protrusions of the lumbar intervertebral disc.

VR could not only create an authentic teaching environment but also help to improve students' psychomotor abilities. By using a VR fused curriculum to replace a traditional 2D course, learners can better apply their anatomical knowledge to clinical problems and master important anatomical structures that require attention during surgery. Moreover, a VR fused curriculum enhances intrinsic engagement and the $3 \mathrm{D}$ spatial visualizations of protrusions of the intervertebral disc for the learners. Our findings showed that almost all students agreed that a VR fused curriculum is attractive, practical, and simple to operate. This indicates that VR technology has enormous potential as an effective teaching method in the future.

In surgical teaching, because the VR technology allows the observer to view and manipulate the models at will, instructors can intuitively and accurately point out the surgical approach and simulate the surgical procedures in a simplified way. After the teacher's presentation, students can review the surgical procedures via hands-on exercises. On the basis of a 3D anatomical perspective, students can obtain a better understanding of clinical manifestations and surgical principles. Moreover, VR technology alleviates the shortage of clinical cases and provides more learning materials for students. For the assessment of clinical surgical skills, VR technology can also be used as a realistic tool, demonstrating its ability to differentiate between various levels of experience. . $^{24,26}$

Notably, this VR fused curriculum integrated anatomi- 


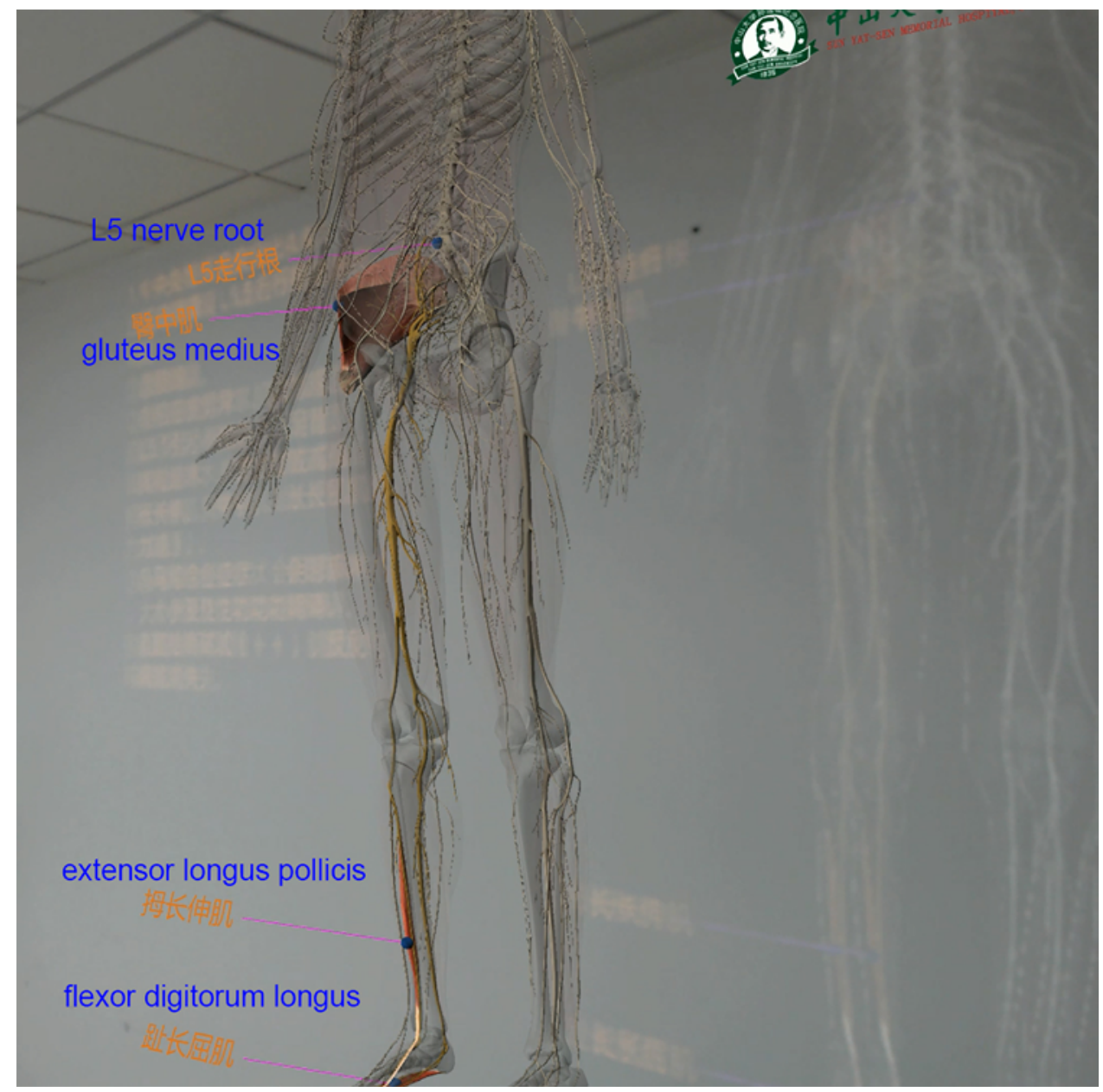

FIG. 3. The affected muscles after pinching on the $L 5$ nerve root in this clinical case. Gluteus medius, extensor longus pollicis, and flexor digitorum longus muscles, which were innervated by the $\mathrm{L} 5$ nerve in central-type LDH.

cal structure and orthopedics, and the students were junior doctors or postgraduates rather than undergraduates. This is especially indispensable when considering that an obvious decline in the time allocated to clinical anatomy has become apparent. Given the current situation, junior doctors are willing to spend more time to consolidate intrinsic connections of anatomical structures and LDH using additional curriculum to bridge their knowledge gaps..$^{27}$ Considering the reduced training time of surgeons, it is necessary to exploit more advanced and technical means to increase the speed of learning. ${ }^{28}$ Because of the close link between anatomy and orthopedics, this fused curriculum is different from integrating virtual devices into preclinical courses, including physiology, pathophysiology, and pharmacology, for medical students, as reported in a recent study. ${ }^{29}$

A VR-based basic and clinical fused curriculum is a beneficial learning procedure. A VR fused education is convenient, repeatable, realistic, and almost noninvasive. Junior surgeons can repeatedly plan and comprehend the regional anatomy of an individual patient's $\mathrm{LDH}$, thereby achieving a good surgical outcome. Herein, we also pro- vide a teaching video on the VR fused curriculum that was used in the present study. Video 1 shows shift, navigation, and deeper structures, and Video 2 shows the affected muscles innervated by the L5 nerve in this case.

VIDEO 1. The lecturer and students discuss the virtual elements of the digital anatomical model both for standard lumbar anatomy and LDH using a remote-control gestures. All virtual parts can be freely rotated, zoomed, shifted, and navigated by toggling dozens of builtin annotations. After the teacher's presentation, students can review the surgical procedures via hands-on exercises. Copyright Chunhai Li. Published with permission. Click here to view.

VIDEO 2. A 53-year-old man complained of low-back pain and leg pain, with symptoms of paresthesia and numbness of the lower limbs, as well as weakness of the gluteus medius, extensor longus pollicis, and flexor digitorum longus muscles. CT and MRI confirmed the diagnosis of LDH and L5 nerve root compression in this patient. The VR model shows the gluteus medius, extensor longus pollicis, and flexor digitorum longus muscles, which are innervated by the $L 5$ nerve. The students can clearly observe muscle distributions and nerve dislocations in a virtual environment. By using the VR model, the VR-trained group was fully immersed in a virtual environment that mimics the characteristics of real human anatomy through 3D glasses. The model is color-coded to distinguish the regional neuroanatomy. It is very beneficial to the students for understanding the anatomical 

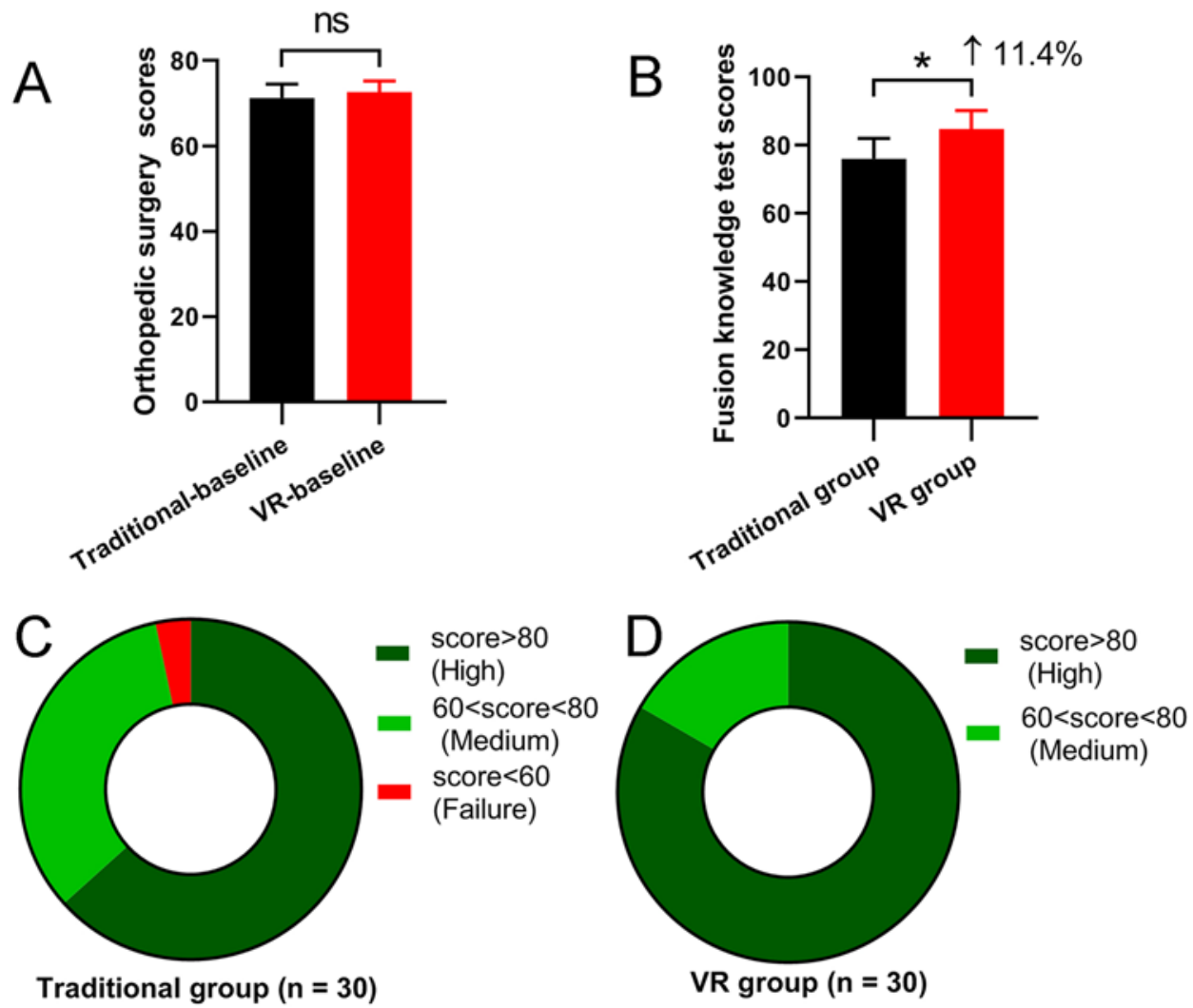

FIG. 4. A: The orthopedic surgery scores were considered as baseline levels for the traditional and VR groups. B: The overall mean scores achieved in the anatomical and clinical fusion knowledge test (mean \pm standard deviation). C and D: The percentage of higher scores, medium scores, and low scores in the VR teaching group (D) and controls (C). Number of participants: VR group $(n=30)$; traditional group $(n=30)$. $n s=$ not significant. Independent sample t-test $\left(2\right.$-tailed), ${ }^{*} p<0.05 ; p<0.05$ represents a statistical difference between the two groups.

structures and patient's symptoms. The herniated lumbar disc (traced as a blue spot) compresses on the L5 nerve roots (traced as brown streaks), which causes the symptoms described above. Copyright Chunhai Li. Published with permission. Click here to view.

\section{Study Limitations}

This study is still affected by several limitations, as follows. 1) Interacting with the novel technology is difficult at first, both for instructors and learners; therefore, the VR system still needs to be improved in the future for increased convenience of use. 2) The production of a VRbased fused curriculum is time-consuming, costly, and not very universally available. 3 ) Another limitation is that the study involved a relatively small sample size; therefore, future studies on immersive VR-related curriculums should be conducted on a larger number of students to avoid valuable information loss. 4) Adverse effects such as general discomfort, headache, dizziness, nausea, and disorientation have been reported by another group. ${ }^{30}$ However, in the present study, no obvious adverse effects were observed in the VR teaching group. One possible reason is the relatively small sample of participants, which, as mentioned above, is another limitation of this study. 5) Whether VR technology improves the operative skills and promotes the clinical diagnosis and treatment level of surgeons in the future needs follow-up studies.

\section{Conclusions}

This study demonstrates that immersive VR-based education is more attractive for residents and students than traditional 2D anatomy education. However, a simpler process and easier operation of the VR system are necessary for wider application to clinical preoperative planning in the future. This study indicates that a VR-based basic and clinical fused curriculum can work as a new type of tool for junior doctors to encourage the integration of anatomical knowledge into clinical situations during clinical education.

\section{Acknowledgments}

Professor Li has received funding from the Undergraduate Higher Education Teaching Reform Project of Guangdong Province (2016, No. 236, 2018, No. 1) and the Undergraduate Teaching Quality-Engineering Project of Guangdong (81000-18842502, 81000-18842505, 81000-31911130).

\section{References}

1. Teishima J, Hattori M, Inoue S, Hieda K, Kobatake K, Shinmei $\mathrm{S}$, et al. Effect of spatial cognitive ability on gain in robot-assisted surgical skills of urological surgeons. J Surg Educ. 2016;73(4):624-630.

2. Henn P, Gallagher AG, Nugent E, Seymour NE, Haluck RS, 
Hseino H, et al. Visual spatial ability for surgical trainees: implications for learning endoscopic, laparoscopic surgery and other image-guided procedures. Surg Endosc. 2018; 32(8):3634-3639.

3. Yu P, Wang Y, Wu X, Liu Z, Liu F, Li Q, et al. A digital anatomic investigation of the safe triangle areas for L1-5 percutaneous minimally invasive discectomy. Surg Radiol Anat. 2020;42(2):103-110.

4. Gadjradj PS, van Tulder MW, Dirven CM, Peul WC, Harhangi BS. Clinical outcomes after percutaneous transforaminal endoscopic discectomy for lumbar disc herniation: a prospective case series. Neurosurg Focus. 2016;40(2):E3.

5. Wang F, Ju XC, Song RX. Clinical efficacy and technical characteristics of percutaneous endoscopic lumbar discectomy in the treatment of upper lumbar disc herniation. Article in Chinese. Zhongguo Gu Shang. 2020;33(5):430-434.

6. Moro C, Stromberga Z, Raikos A, Stirling A. The effectiveness of virtual and augmented reality in health sciences and medical anatomy. Anat Sci Educ. 2017;10(6):549-559.

7. Fang Y, Wu H, Tan AD, Cheng L. Transcervical endoscopic approach for parapharyngeal space: a cadaver study and clinical practice. Acta Otolaryngol. 2020;140(2):163-169.

8. Erolin C, Reid L, McDougall S. Using virtual reality to complement and enhance anatomy education. $J$ Vis Commun Med. 2019;42(3):93-101.

9. Uruthiralingam U, Rea PM. Augmented and virtual reality in anatomical education - a systematic review. Adv Exp Med Biol. 2020;1235:89-101.

10. Moro C, Stromberga Z, Stirling A. Virtualisation devices for student learning: comparison between desktop-based (Oculus Rift) and mobile-based (Gear VR) virtual reality in medical and health science education. Australas J Educ Technol. 2017;33:1-10.

11. Birt J, Stromberga Z, Cowling M, Moro C. Mobile mixed reality for experiential learning and simulation in medical and health sciences education. Information (Basel). 2018;9(2):31.

12. Samadbeik M, Yaaghobi D, Bastani P, Abhari S, Rezaee R, Garavand A. The applications of virtual reality technology in medical groups teaching. J Adv Med Educ Prof. 2018;6(3): 123-129.

13. Sattar MU, Palaniappan S, Lokman A, Hassan A, Shah N, Riaz Z. Effects of virtual reality training on medical students' learning motivation and competency. Pak J Med Sci. 2019;35(3):852-857.

14. Grantcharov TP, Kristiansen VB, Bendix J, Bardram L, Rosenberg J, Funch-Jensen P. Randomized clinical trial of virtual reality simulation for laparoscopic skills training. $\mathrm{Br}$ J Surg. 2004;91(2):146-150.

15. Chao C, Chalouhi GE, Bouhanna P, Ville Y, Dommergues M. Randomized clinical trial of virtual reality simulation training for transvaginal gynecologic ultrasound skills. J Ultrasound Med. 2015;34(9):1663-1667.

16. Gerardi M, Cukor J, Difede J, Rizzo A, Rothbaum BO. Virtual reality exposure therapy for post-traumatic stress disorder and other anxiety disorders. Curr Psychiatry Rep. 2010;12(4): 298-305.

17. Jacobsen MF, Konge L, Bach-Holm D, la Cour M, Holm L, Højgaard-Olsen K, et al. Correlation of virtual reality performance with real-life cataract surgery performance. J Cataract Refract Surg. 2019;45(9):1246-1251.

18. Fiani B, De Stefano F, Kondilis A, Covarrubias C, Reier L, Sarhadi K. Virtual reality in neurosurgery: "Can you see it?"-A review of the current applications and future potential. World Neurosurg. 2020;141:291-298.

19. Sabbagh AJ, Bajunaid KM, Alarifi N, Winkler-Schwartz A, Alsideiri G, Al-Zhrani G, et al. Roadmap for developing complex virtual reality simulation scenarios: subpial neurosurgical tumor resection model. World Neurosurg. 2020;139: e220-e229.
20. Bernardo A. Virtual reality and simulation in neurosurgical training. World Neurosurg. 2017;106:1015-1029.

21. Cho J, Rahimpour S, Cutler A, Goodwin CR, Lad SP, Codd P. Enhancing reality: a systematic review of augmented reality in neuronavigation and education. World Neurosurg. 2020; 139:186-195.

22. Lohre R, Wang JC, Lewandrowski KU, Goel DP. Virtual reality in spinal endoscopy: a paradigm shift in education to support spine surgeons. J Spine Surg. 2020;6(1)(suppl 1): S208-S223.

23. Shao X, Yuan Q, Qian D, Ye Z, Chen G, le Zhuang K, et al. Virtual reality technology for teaching neurosurgery of skull base tumor. BMC Med Educ. 2020;20(1):3.

24. Lewis TL, Burnett B, Tunstall RG, Abrahams PH. Complementing anatomy education using three-dimensional anatomy mobile software applications on tablet computers. Clin Anat. 2014;27(3):313-320.

25. Sirimanna P, Gladman MA. Development of a proficiencybased virtual reality simulation training curriculum for laparoscopic appendicectomy. ANZ J Surg. 2017;87(10):760-766.

26. Rizzetto F, Bernareggi A, Rantas S, et al. Immersive virtual reality in surgery and medical education: diving into the future. Am J Surg. 2020;220(4):856-857.

27. Singh R, Tubbs RS, Gupta K, Singh M, Jones DG, Kumar R. Is the decline of human anatomy hazardous to medical education/profession?-A review. Surg Radiol Anat. 2015;37(10): $1257-1265$

28. Das S, Mitchell P. Comparison of three aids for teaching lumbar surgical anatomy. Br J Neurosurg. 2013;27(4):475478.

29. Nicolaou P, McCrorie P, Nicolaou SA. Using virtual patients to integrate physiology, pathophysiology, and pharmacology in preclinical teaching. Adv Physiol Educ. 2019;43(3):277281.

30. Parkhomenko E, O'Leary M, Safiullah S, Walia S, Owyong $\mathrm{M}$, Lin C, et al. Pilot assessment of immersive virtual reality renal models as an educational and preoperative planning tool for percutaneous nephrolithotomy. J Endourol. 2019; 33(4):283-288.

\section{Disclosures}

The authors report no conflict of interest concerning the materials or methods used in this study or the findings specified in this paper.

\section{Author Contributions}

Conception and design: Li. Acquisition of data: Qi, Wang, Chen. Analysis and interpretation of data: Qi, Gan, Wang, Tie. Drafting the article: Qi, Gan, Wang. Approved the final version of the manuscript on behalf of all authors: Li.

\section{Supplemental Information \\ Videos}

Video 1. https://vimeo.com/559931287.

Video 2. https://vimeo.com/559931350.

\section{Correspondence}

Chunhai Li: Sun Yat-sen Memorial Hospital, Sun Yat-sen University, Guangzhou, Guangdong, China. chunhaili@163.com. 